and the benefit that clinical undergraduate teaching could bring in complementing the preclinical and the postgraduate teaching-despite what to many observers must seem overwhelming advantages, conflicting voices continue to cause hesitation in the university.

At the end of the debate (which he found confusing) Sir Joseph Hutchinson, F.R.S., professor of agriculture, said he was not sure whether anybody was " against having a medical school." He thought their trouble was that they were frightened of it. Certainly arguments were advanced that the increase in numbers of teachers needed for clinical teaching would upset the present balance in the Regent House. And it was suggested too that "if a group of subjects, strongly united by professional loyalty, is allowed to attain a dominant position within the University, and if in addition that group can enlist the support of powerful organizations outside the University, then its pressure upon the central bodies will become irresistible in all matters in which its own interests are in conflict with the interests of the University as a whole."

It may seem strange that voices at Cambridge should express anxieties about contact with the medical profession that are not particularly notable at other universities where medical schools thrive, especially in view of the relatively large size of Cambridge University, the variety and strength of its other faculties, and the stability that a long history may be expected to confer. But the source of the worry is the university's unique attitude to the payment of its teachers, for unlike other universities it declines to make differential payment for clinical responsibility. Though the University Grants Committee has authorized the payment of differential salary scales, the university's Regent House decided in $1961^{4}$ that " scales of University stipend be the same for all officers in the same grade whatever the Faculty or Department to which they are attached." What some people in Cambridge now fear is that the creation of a full medical school would give the medical faculty such influence in the affairs of the university that its settled policy on equal stipends would be overborne.

If Cambridge continues to hold out against the recommendation of the University Grants Committee, the practice of other universities, and the policy of the profession, it would certainly have great difficulty in establishing the complete medical school that so many would like to see there. But the departments of physiology, biochemistry, and anatomy in particular that have made such great contributions to the advancement of medicine have recently been joined by a postgraduate school that is beginning to show some of the great potentiality Cambridge could have in the teaching of clinical medicine. It would be sad indeed if the university's fine traditions and present excellence are not directed to undergraduate clinical teaching also.

\footnotetext{
1 Royal Commission on Medical Education, 1965-68, Report, 1968, Cmnd. 3569. London, H.M.S.O.

2 See British Medical fournal, 1969, 1, 855.

3 Cambridge University Reporter, 30 April 1969.

- British Medical fournal, 1961, 1, 419.
}

\section{Nutrition and Age}

The nutritional requirements of the elderly have not yet been clearly defined, but present indications are that a phase of subclinical malnutrition may affect some of them, leading to poor health, apathy, and disinterest. ${ }^{1}$ All workers in this field agree that dietetic guidance should start before the age of 65 and that an adequate income is essential if basic nutritional needs are to be met. J. D. Paulett and Jean D. Buxton $^{2}$ found that if any miscalculation in budget occurred the economies are made in food and reported that diet was inadequate in $50 \%$ of a series of older people in a sheltered area compared with $9 \%$ living in the community. Local authorities could improve matters by seeking the advice of dietitians in the instruction of home helps and in preparation of meals-on-wheels. It may be noted that sensation of taste is diminished in the elderly, and this in itself may alter the choice of food.

The problem of food supplementation is extremely complex. P. C. Elwood ${ }^{3}$ observed no significant difference in haemoglobin level between a sample of 113 anaemic women supplied with bread made from flour with added iron and another group of 124 anaemic women given ordinary bread for periods of nine months. Much work has been done recently in sideropenia (serum iron below $50 \mu \mathrm{g}$. per $100 \mathrm{ml}$.) and D. E. B. Powell and his colleagues ${ }^{4}$ described this condition in $39 \%$ of the men and $41 \%$ of the women admitted to the acute geriatric wards of a general hospital. Serum iron could not be correlated with haemoglobin levels, but the authors suggested that the low levels of serum iron were significant because they were associated with raised total ironbinding capacity and lowered iron saturation. Further inves- tigation has shown that nearly half of an elderly hospital population have a raised total iron binding capacity (above $400 \mu$ g. per $100 \mathrm{ml}$.), and Powell and his coworkers ${ }^{5}$ consider that, unless evidence is found to the contrary, this finding must be due to widespread iron deficiency.

Clinical evaluation of subclinical malnutrition presents great difficulty. This week Dr. J. Andrews and his colleagues report in the B.M.f. that they were unable to confirm that sublingual lesions could be improved by supplementing the diet with vitamin $\mathrm{C}$. On histological examination the lesions were found to be aneurysmal dilatation of the venules. These authors noted that 9 months' supplementation of $40-80 \mathrm{mg}$. daily of vitamin $C$ was necessary before the vitamin levels in leucocytes reached those found in younger people. G. Taylor ${ }^{6}$ believed there was a possible connexion between "senile purpura," "sublingual petechial haemorrhages," and chronic vitamin C deficiency. However, no relation has been shown between vitamin $\mathrm{C}$ status and senile purpura. ${ }^{78}$. R. I. Russell and his colleagues ${ }^{9}$ have suggested that subclinical scurvy may be an additional factor in maintaining haemorrhage from the gastrointestinal tract initially precipitated by aspirin or alcohol, and that poor dietary intake of vitamin $\mathrm{C}$ seems the most probable explanation for the low leucocyteascorbic-acid levels observed. The leucocyte-ascorbic-acid levels in patients admitted to hospital with gastrointestinal haemorrhage were significantly lower than those in patients with uncomplicated peptic ulcer or in healthy controls. The difference was much more striking over the age of 45 . The leucocyte-ascorbic-acid level fell steadily with advancing age in the patients with gastrointestinal haemorrhage and in those with uncomplicated peptic ulcer. The level did not vary with age in the healthy controls. 
While it may be pedantic to classify partial gastrectomy as a cause of iatrogenic malabsorption, patients who have had this operation must be followed up carefully and for long periods. Loss of weight, anaemia, steatorrhoea and bone changes ${ }^{10}$ have been described, and I. D. A. Johnston and his colleagues ${ }^{11}$ showed that if patients with partial gastrectomies can be persuaded to eat sufficient food their weight will increase, while H. S. Hillman ${ }^{12}$ reported weight gain and reduction in steatorrhoea after the administration of pancreatic enzyme. Intestinal malabsorption of fat and vitamin $\mathbf{B}_{12}$ and deficiency of folic acid have been reported during treatment of pulmonary tuberculosis with para-aminosalicylic acid, the malabsorption improving when P.A.S. was withdrawn. ${ }^{13}$ It is of interest to note that impairment of memory was attributed to isoniazid, ${ }^{14}$ but these patients were also receiving P.A.S. Liquid paraffin and broad-spectrum antibiotics can interfere with absorption of essential nutriments.

Atrophic gastritis is common in the elderly even in the absence of gastrointestinal symptoms. ${ }^{15} 16$ The consequent reduction in secretion of acid and intrinsic factor results sometimes in impaired absorption of vitamin $B_{12}$, and in such cases additional factors such as chronic infection, which increase requirements for vitamin $B_{12}$, or severe dietary deficiency may produce pathological reduction of vitamin $\mathbf{B}_{12}$ in the serum. Borderline levels of serum $B_{12}$ are not uncommon in elderly people, but the significance of such findings is not clear. ${ }^{17}$ Serum folate is likewise sometimes found to be low in elderly patients admitted to institutions. ${ }^{18}$

While none of their patients were elderly, C. E. Denton and $R$. Smith, ${ }^{19}$ in a study of nutritional osteomalacia, conclude that this illness in adults is mainly due to dietary lack of vitamin $\mathrm{D}$ and will develop when the diet contains less than about 70 units of vitamin $\mathrm{D}$ per day. The usual history is of avoidance of fatty foods or of being a strict vegetarian.

To the general practitioner the problem of nutrition of the elderly appears complex. There may exist a high-risk group of people over 65 (advancing age makes little difference) who spend, for various reasons, less than they should on food. Some are depressed and apathetic, perhaps recently bereaved ; some have the constant fear of ultimate poverty; others are

1 British Medical fournal, 1968, 3, 629.

- Paulett, J. D. and Buxton J. D., British Medical fournal, 1969, 1, 432.

- Elwood, P. C., Lancet, 1968, 2, 516.

- Powell, D. E. B., Thomas, J. H., and Mills, P., Gerontologia Clinica, 1968, 10, 21.

- Powell, D. E. B., and Thomas, J. H. Gerontologia Clinica, 1969, 11,

Taylor, G., Lancet, 1966, 1, 926. 'Tattersall, R. N., and Seville, R., Quarterly fournal of Medicine, 1950,
19, 151.

- Andrews, J., and Brook, M., Lancet, 1966, 1, 1350.

- Russell, R. I., Williamson, J. M., Goldberg, A., and Wares, E., Lancet, 1968, 2, 603.

10 British Medical fournal, 1969, 1, 396. 11 Johnston, I. D. A., Welbourn, R., and Acheson, K., Lancet, 1958, 1,
1242.

12 Hillman, H. S., Gut, 1968, 9, 576.

13 Akhtar, A. J., Crompton, G. K., and Schonell, M. E., Tubercle, 1968, 49, 328.

- Olsen, P. Z., and Torning, K., Scandinavian fournal of Respiratory Diseases, 1968, 49, 1.

15 Hradsky, M., Groh, J., Langr, F. and Herout, V., Gerontologia Clinica, 1966, 8, 164.

Andrews, G. R., Haneman, B., Arnold, B. J., Cooper Booth, J., and Taylor, K., Australasian Annals of Medicine, 1967, 16, 230.

17 Cape, R. D. T., and Shinton, N. K., Gerontologia Clinica, 1961, 3,
163.

Read, A. E., Gough, K. R., Pardoe, J. L., and Nicholas, A., British Medical fournal, 1965, 2, 843.

Denton, C. E., and Smith, R., Quarterly fournal of Medicine, 1969,
38, 195. mildly confused ; and a few have esoteric food habits. There is also a group who are immobile because of physical disease and who depend on others for their food ; those who require prolonged analgesic therapy, especially with aspirin, should be included. Some older people will come to the doctor complaining of lassitude, apathy, and weakness, and these symptoms call for further investigation. Apart from obvious anaemia, such a syndrome may indicate sideropenia, potassium deficiency, and perhaps deficiency of vitamin $\mathrm{C}$, vitamin $B_{12}$, or folate. Unfortunately such symptoms in the elderly are non-specific and may also be a manifestation of incipient cerebrovascular disease, intercurrent acute infection, or depression. There are, however, clear indications for giving dietary advice and vitamin supplements to any older person who has recently had a febrile illness, undergone a surgical operation, or sustained injury.

\section{Transferable Drug Resistance}

Transferable drug resistance is now often in the news, the lay press having seized on it as a threat to human health demanding drastic restrictions on the use of antibiotics, particularly in animals. First recognized in Japan in 1956, it was for some years studied exclusively in that country, and mainly in dysentery bacilli. The first report of its occurrence in Europe dates from 1962, and was by Naomi Datta, ${ }^{1}$ the author of a further paper on the subject in this issue of the B.M.F. at page 407. Continental workers followed, but, strangely enough, no interest in the subject appears to have been taken until 1966 in the United States, whose many workers are usually so much to the fore in new developments of this kind.

Transferable resistance occurs only in enterobacteria and a few other genera of Gram-negative bacilli, and is thus of practical interest only in bacteria usually inhabiting the lower alimentary tract. Genetic material conferring resistance may be either chromosomal and non-transferable, or extrachromosomal in the form of genetic particles which have been variously referred to as plasmids, episomes, or R-factors, which are capable of transference to another bacterial cell by conjugation. It is almost incredible but true that if two cultures are mixed, one of them possessing this form of resistance to certain drugs, a small proportion of the cells in the second culture will acquire this resistance within a few minutes. It is by means of such mixtures of a resistant with a sensitive culture of another species that it can be decided whether the resistance of the first is transferable (or "infectious"). This transference, which occurs so readily in a tube of broth, undoubtedly goes on in the bowel, though probably not with the same facility, since physical separation by elements in the bowel contents reduces the opportunities of contact. This means that if any organism carrying $R$ factors is swallowed these may be transmitted to part of the normal population of the bowel and thence, if opportunity occurs, perhaps to some pathogenic species. Until these discoveries it had always been supposed that drug resistance had resulted from exposure to the drug, either during treatment of the patient from whom the organism was isolated or of someone else from whom it was derived. We now know that no such exposure may ever have occurred: resistance may merely have been transferred from another organism. 